\title{
Clinico-Epidemiological Profile of Dermatophyte Infections in Children at a Tertiary Care Hospital in Mathura
}

\author{
Harsh Sharma ${ }^{1}$, Rakesh Kumar Chawla ${ }^{2}$ \\ ${ }^{1}$ Assistant Professor, K.D. Medical College Hospital and Research Center, Mathura, Uttar Pradesh, India, ${ }^{2}$ Associate Professor, Department of Dermatology, K.D. \\ Medical College Hospital and Research Center, Mathura, Uttar Pradesh, India.
}

\section{Abstract}

Background: Dermatophytosis is one of the most common cutaneous fungal infections of public health concern affecting children, adolescents and adults. Thus, the present study was undertaken to assess the clinico-epidemiological profile of dermatophyte infections in children. Subjects and Methods: This study was conducted among 80 clinically suspected cases of dermatophytoses. Patients under antifungal treatment for $>4$ weeks and non-dermatophytic fungal infections were excluded from the study. Samples were collected from affected lesions. The statistical analysis was done using chi square test and p value of $<0.05$ was considered significant. Results: Most common age group in the study was 8-10 years. Tinea cruris was observed most common dermatophyte condition in boys whereas Tinea unguium was predominant in girls. Tinea unguium infections were common in age group 8-10 years. This study shows that most dermatophyte infections were prevalent in age group of 8-10 years. Conclusion: There are several risk factors which can cause dermatophytoses. Poor hygiene and topical steroid usage were the major risk factors which was responsible for spreading dermatophytoses. People should be educated regarding personal hygiene and sanitary control to reduce the risk of dermatophytoses.

Keywords: Clinico-Epidemiological, Dermatophyte, Cutaneous, Tinea unguium.

Corresponding Author: Dr. Rakesh Kumar Chawla, Associate Professor, Department of Dermatology, K.D. Medical College Hospital and Research Center, Mathura, Uttar Pradesh, India.

Received: June 2019

Accepted: June 2019

\section{Introduction}

Dermatophytes are parasitic fungi that infest the skin and cause infections of the skin, hair and nails because of their ability to obtain nutrients from keratinized material. These organisms colonize the keratin tissues and in response to their metabolic byproducts, host experiences inflammatory reactions. $^{[1]}$ The organisms belong to 3 genera, Trichophyton, Epidermophyton and Microsporum. Dermatophytes may be grouped into 3 categories based on host preference and natural habitat. Anthropophilic species predominantly infect humans, Geophilic species are soil based and may infect both humans and animals, and Zoophilic species generally infect non-human mammals. ${ }^{[2]}$ Traditionally infections caused by dermatophytes have been named according to the anatomical locations involved, by appending the Latin term designating the body site after the word Tinea. ${ }^{[3]}$ Dermatophytosis is a major public health concern in the world today. Dermatophytosis is common in tropical countries like India and may reach epidemic proportion in areas with high rate of humidity, over population and poor hygienic conditions. ${ }^{[4]}$ The disease is more frequent among men than woman. There are many causes that increase the prevalence of disease such as trauma, increased sweating and diabetes. ${ }^{[5]}$ The present study was undertaken to assess the Clinico-Epidemiological profile of Dermatophyte infections in children.

\section{Subjects and Methods}

Present observational study conducted at Department of Dermatology, K.D. Medical College Hospital and Research Center, Mathura, Uttar Pradesh, India. The study population comprised of 80 clinically suspected cases of dermatophytoses. Patients under antifungal treatment for $>4$ weeks and non-dermatophytic fungal infections were excluded from the study. The written informed consent was taken from the subjects and from their parents. This study was approved by the ethical committee of the institute. Relevant clinical history and detailed examination of the lesion was done.

\section{Collection of the Sample}

Samples were collected from affected lesions. Whenever the patients presented with lesions at clinically different sites samples were collected from all those sites and each of these were processed and examined individually. After cleaning the affected area with $70 \%$ ethanol, skin scrapings were taken with sterile scalpel from the active edge of the lesions. In case of nail infections, clippings and scrapings are taken from friable or discolored areas of hyperkeratotic nails. Hair clippings were taken is cases of scalp infection. Scrapings/clippings were sent to lab for easy visualization of specimens and processed for direct microscopy and culture techniques. The statistical analysis was done using 
chi square test and $\mathrm{p}$ value of $<0.05$ was considered significant.

\section{Results}

A total sample size of this study was 80 in which 47 were boys and 33 were girls of age group 5-13 years. Most common age group in the study was 8-10 years. Tinea cruris was observed most common dermatophyte condition in boys whereas Tinea unguium was predominant in girls. Tinea unguium infections were common in age group 8-10 years. This study shows that most dermatophyte infections were prevalent in age group of 8-10 years.

\section{Table 1: Distribution of gender}

\begin{tabular}{|l|l|l|}
\hline Gender & $\mathbf{N}(\boldsymbol{\%})$ & p-value \\
\hline Boys & $47(58.75 \%)$ & $<0.05$ \\
\hline Girls & $33(41.25 \%)$ & \\
\hline Total & $80(100 \%)$ & \\
\hline
\end{tabular}

\begin{tabular}{l}
\hline Table 2: Distribution of gender on the basis of age group \\
\begin{tabular}{|l|l|l|}
\hline Age Group & Number of cases \\
\cline { 2 - 3 } & Boys $(\mathbf{n}=\mathbf{4 7})$ & Girls $(\mathbf{n}=\mathbf{3 3})$ \\
\hline $5-7$ years & 8 & 5 \\
\hline $8-10$ years & 21 & 15 \\
\hline $11-13$ years & 18 & 13 \\
\hline
\end{tabular}
\end{tabular}

Table 3: Distribution of dermatophyte infections

\begin{tabular}{|l|l|l|}
\hline \multirow{2}{*}{ Dermatophyte infections } & \multicolumn{2}{|l|}{ Total no. of samples $\mathbf{n}=\mathbf{8 0}$} \\
\cline { 2 - 3 } & Boys $=\mathbf{4 7}$ & Girls $=\mathbf{3 3}$ \\
\hline T. unguium & 8 & 9 \\
\hline T.capitis & 4 & 3 \\
\hline T. pedis & 5 & 3 \\
\hline T. cruris & 12 & 8 \\
\hline T. faciei & 7 & 4 \\
\hline T. corporis & 9 & 5 \\
\hline T. manum & 2 & 1 \\
\hline
\end{tabular}

Table 4: Distribution of sample with respect to dermatophyte infections and age

\begin{tabular}{|l|l|l|l|l|}
\hline $\begin{array}{l}\text { Dermatophyte } \\
\text { infections }\end{array}$ & $\begin{array}{l}\text { Total } \\
\text { number of } \\
\text { sample }\end{array}$ & $\begin{array}{l}\text { Age 5-7 } \\
\text { years }\end{array}$ & $\begin{array}{l}\text { Age 8- } \\
\mathbf{1 0} \\
\text { years }\end{array}$ & $\begin{array}{l}\text { Age } \\
\mathbf{1 1 - 1 3} \\
\text { years }\end{array}$ \\
\hline T. unguium & 17 & 4 & 8 & 5 \\
\hline T.capitis & 7 & 1 & 3 & 3 \\
\hline T. pedis & 8 & 1 & 4 & 3 \\
\hline T. cruris & 20 & 2 & 11 & 7 \\
\hline T. faciei & 11 & 3 & 3 & 5 \\
\hline T. corporis & 14 & 1 & 5 & 8 \\
\hline T. manum & 3 & 1 & 2 & 0 \\
\hline Total & 80 & 13 & 36 & 31 \\
\hline & & \multicolumn{2}{|l}{} \\
\hline
\end{tabular}

\section{Discussion}

Dermatophytes parasitize keratin rich tissues and produce dermal inflammatory response. This leads to redness, intense itching/burning in turn causes cosmetically poor appearance. 6 The severity of the infection depends on various factors like immune reactions of the host to the fungal metabolic products, virulence of infecting strain, anatomical location of the infection and environmental factors. ${ }^{[7]}$ Among 80 clinically diagnosed cases of dermatophytosis, tinea unguium was the most common clinical types in girls whereas Tinea cruris was observed most common dermatophyte condition in boys. Tinea unguium infections were common in age group 8-10 years. This study shows that most dermatophyte infections were prevalent in the age group of 8-10 years.

A study conducted by Hosthota $\mathrm{A}$ et al reveals that Tinea cruris was the commonest clinical type (50\%) followed by Tinea corporis (18.4\%) and Tinea unguium (11.9\%). Trichophytonrubrum was the aetiological agent isolated in majority (33\%), followed by Trichophytonmentagrophytes $(20 \%) .{ }^{[8]}$

Results of study conducted by Chaudhary et al shows that males were $88 \%$ more prone to dermatophytoses than females in total positive case. Tinea cruris was the most common clinical presentation and Trichophytonrubrum was the most common fungal pathogen isolated from clinical samples. This study analyzed the Dermatophytic infections are prevalent throughout the world-due to a lack of education or resources for diagnosis and became a larger threat. ${ }^{[9]}$ Similar study conducted by Gupta $\mathrm{CM}$ et al concluded that Tinea unguium $(52.0 \%)$ was predominant clinical condition. Males were affected more $(79.0 \%)$ than females. Dermatophytosis was predominantly found in more than 60 years $(32.0 \%)$ and $31-45$ years $(24.0 \%)$. Fungi were demonstrated in $55.0 \%$ cases by $\mathrm{KOH}$ mount and $46.0 \%$ cases were positive by culture. $16.0 \%$ cases were $\mathrm{KOH}$ negative and culture positive. Trichophyton rubrum $(41.0 \%)$ was the predominant species. ${ }^{[10]}$

\section{Conclusion}

This study recognized that Tinea cruris was observed most common dermatophyte condition in boys whereas Tinea unguium was predominant in girls. Tinea unguium infections were common in age group 8-10 years. This study shows that most dermatophyte infections were prevalent in age group of 8-10 years. There are several risk factors which can cause dermatophytoses. Poor hygiene and topical steroid usage were the major risk factors which was responsible for spreading dermatophytoses. People should be educated regarding personal hygiene and sanitary control to reduce the risk of dermatophytoses.

\section{References}

1. Garg J, Tilak R, Garg A, Prakash P, Gulati A K \&Nath G. Rapid detection of dermatophytes from skin and hair. BMC Res. Notes., 2009: 18: 2:60.

2. Gupta A K, Chaudhry M \&Elewski B. Tinea corporis, Tinea cruris, Tinea nigra, and piedra. Dermatol. Clin., 2003; 21: 395-400.

3. Hay RJ, Moore M. Mycology. Rook s textbook of dermatology. Burns T, Breathnach S, Cox Griffiths C, editors. 7th edition. London; Blackwel Science; 2004: 31.1-31.101.

4. Madhavi S, Rama Rao MV, Jyothsna K. Mycological study of dermatophytosis in rural population. Annals of Biological Research 2011;2(3): 88-93.

5. Noble SL, Forbes RC Stamm PL. Diagnosis and management of common tinea infections. Am Fam Physician 1998; (10): 2424-32. 


\section{Sharma of Chaula; Clinica-Epidemialagical Prafile of Dermataphyte Infections in Children at a Tertiany}

\section{Care Htaspital in Mathura}

6. Mishra M, Mishra S, Singh P C, Mishra B C. Clinico-mycological profile of superficial mycoses. Indian $\mathrm{J}$ DermatolVenereolLeprol. 1998;64:283-5.

7. Poluri LV, Indugula JP, Kondapaneni SL. Clinicomycological Study of Dermatophytosis in South India. J Lab Physicians. 2015;7:84-9.

8. Hosthota A, Gowda T, Manikonda R. Clinical profile and risk factors of dermatophytoses: a hospital based study. Int J Res Dermatol 2018;4:508-13.
9. Jitendra Kumar Chaudhary, Ankur Kumar. A Clinico - Mycological Profile of Dermatophytosis at a Tertiary Care Hospital in Bihar. Int. J. Curr. Microbiol. App. Sci. 2016; 5(2): 181-89.

10. Gupta CM, Tripathi K, Tiwari S, Rathore Y, Nema S, Dhanvijay AG. Current trends of Clinico mycological profile of Dermatophytosis in Central India. IOSR-JDMS. 2014;13(10):23-6.

Copyright: () the author(s), 2019. It is an open-access article distributed under the terms of the Creative Commons Attribution License (CC BY 4.0), which permits authors to retain ownership of the copyright for their content, and allow anyone to download, reuse, reprint, modify, distribute and/or copy the content as long as the original authors and source are cited.

How to cite this article: Sharma H, Chawla RK. Clinico-Epidemiological Profile of Dermatophyte Infections in Children at a Tertiary Care Hospital in Mathura. Asian J. Med. Res. 2019;8(2):DT08-DT10.

DOI: dx.doi.org/10.21276/ajmr.2019.8.2.DT3

Source of Support: Nil, Conflict of Interest: None declared. 